\title{
Controladoria em Instituição pública de Ensino Superior: Percepção do seu papel sob a ótica dos gestores
}

\author{
Doutorado em Controladoria e Contabilidade pela Universidade do Vale do Rio dos \\ Sinos - UNISINOS \\ Professor da Universidade do Vale do Rio dos Sinos - UNISINOS \\ Avenida Unisinos, 950. Bairro Cristo Rei. São Leopoldo/RS. CEP: 93022-000 \\ E-mail:marcosas@unisinos.br

\begin{abstract}
Almir Rodrigues Durigon Mestrado em Ciências Contábeis pela Universidade do Vale do Rio dos Sinos UNISINOS

Professor da Universidade do Estado de Mato Grosso - UNEMAT Avenida dos Ingás, 3001. Bairro Jardim Imperial. Sinop/MT. CEP: 78550-000 E-mail: almir_durigon@hotmail.com
\end{abstract}

\section{RESUMO}

O objetivo do artigo é identificar, na percepção dos gestores da Universidade do Estado de Mato Grosso - UNEMAT, o papel da controladoria no alcance da eficácia institucional. A pesquisa foi conduzida por meio de estudo de caso único, caracterizando-se como descritiva quanto aos objetivos e envolvendo aspectos quantitativos e qualitativos na abordagem do problema. A coleta de dados deu-se por meio de questionário estruturado com escalas do tipo Likert de cinco pontos, aplicado pessoalmente pelos pesquisadores no $4^{\circ}$ trimestre de 2011. Para análise quantitativa dos dados utilizou-se a mensuração do ranking médio das escalas. Os gestores respondentes da UNEMAT foram agrupados em gestores da reitoria e coordenadores de campi. Os principais resultados revelam que: (a) há reconhecimento da maioria dos gestores de que a controladoria contribui para o fortalecimento e desenvolvimento da instituição; (b) é necessário que todos conheçam melhor a aplicabilidade da controladoria dentro da instituição; (c) a falta de estrutura física e humana mais adequada dificulta o melhor desenvolvimento da controladoria; (d) a controladoria precisa atuar mais proficuamente na elaboração do orçamento e projeção de cenários. Há reconhecimento geral que a controladoria ainda pode avançar muito nas suas atividades e contribuição à gestão da IES.

Palavras-chave: Controladoria. Instituição Pública de Ensino. Eficácia Institucional.

Controllership in public Institution of higher education: Perception of their role in the managers perspective 
Controladoria em Instituição pública de Ensino Superior: Percepção do seu papel sob a ótica dos

gestores

Marcos Antonio de Souza, Almir Rodrigues Durigon

\section{ABSTRACT}

This paper aims to identify the perceptions of State University of Mato Grosso UNEMAT managers about the role of controllership to reach the institutional effectiveness. The research was conducted through a single case study, characterized as descriptive and involving quantitative and qualitative approach in analysis process. Data collection was conduct through a structured questionnaire with Likert scales of five points, applied personally by the researchers during the 4th quarter of 2011. For quantitative data analysis was used the average ranking of the scales. The UNEMAT managers respondents were grouped into the rectory managers and campuses coordinators. The main results show that: (a) there is recognition by the majority of managers that controllership contributes to the strengthening and development of the institution; (b) is necessary for everyone to know better the applicability of the controllership within the institution; (c) there are lack of physical infrastructure and human resources to most appropriate contribution by controllership; (d) the controllership needs to operate more profitably in aid of budgeting and forecasting scenarios. In general there is recognition that the controllership can still go a long way in their activities to best contribution to institution management.

Keywords: Controllership. Public Institution of Education. Institutional Effectiveness.

\section{INTRODUÇÃO}

As discussões envolvendo as Instituições de Ensino Superior - IES brasileiras se apresentam de várias e diferentes formas, sempre abrangendo análises e interpretações sobre suas histórias, impasses, desafios e forma como administram seus recursos. Nessa acepção, conforme Venturini et al. (2010), as IES públicas são constantemente questionadas sobre a qualidade de suas atividades e a maneira como administram os recursos que a sociedade coloca à sua disposição.

Segundo Ismail (2010), as IES a exemplo de outras organizações, estão sendo administradas em ambiente turbulento, incerto, dinâmico e desafiador. A revolução digital mudou fundamentalmente a forma de administrar, e nesses ambientes em rápida transformação medidas devem ser tomadas para responder positivamente a esses desafios. Para Venturini et al. (2010), as IES precisam manter qualidade acadêmica e administrativa, requisitos para credibilidade e legitimidade junto à sociedade. 
Controladoria em Instituição pública de Ensino Superior: Percepção do seu papel sob a ótica dos

gestores

Marcos Antonio de Souza, Almir Rodrigues Durigon

As discussões em relação à organização das entidades públicas têm aumentado significativamente. Linna et al. (2010) esclarecem que nunca se discutiu tanto os aspectos da produtividade, da eficiência dos processos e decisões no setor público. Para os autores isso reflete o reconhecimento de que a produtividade do setor público é tão importante quanto à do setor privado para o desenvolvimento econômico de um país e em benefício dos cidadãos. Secchi (2009) e Hood e Peters (2004) também reconhecem que desde a década 1980 as administrações públicas vêm realizando transformações substanciais, e que muitas delas decorrem da implantação de aprendizados originados do setor privado.

Nesse ambiente de transformações na forma de executar a gestão pública, a controladoria surge como uma atividade que pode trazer contribuições relevantes. Guimarães et al. (2009) enfatizam que as atividades de controladoria tendem a propiciar aos gestores instrumentos que permitem uma visão holística das aplicações de recursos que estão sendo empregadas na entidade, a fim de verificar como suas metas poderão ser alcançadas e, dessa forma, tomar as melhores decisões. Lima et al. (2011) afirmam que a controladoria oferece instrumentos capazes de permitir que a organização ser conduzida para o alcance dos melhores resultados. Slomski (2005) também trata das características da controladoria com foco específico da sua atuação na gestão pública.

Depreende-se, desse breve contexto, a necessidade de se conhecer o estágio de atuação de organizações públicas, inclusive como forma de avançar na sua contribuição para uma gestão eficaz, mais especificamente, no caso deste estudo, de uma IES. Surge, assim, o objetivo deste estudo em identificar como os gestores da Universidade do Estado de Mato Grosso - UNEMAT percebem o papel da controladoria no alcance da eficácia institucional.

Dessa forma, partindo-se da premissa de que a adesão aos pressupostos básicos de eficiência e eficácia institucional tem sido discutida nos órgãos públicos, e de que a controladoria pode favorecer o desenvolvimento da instituição, a pesquisa 
Controladoria em Instituição pública de Ensino Superior: Percepção do seu papel sob a ótica dos

gestores

Marcos Antonio de Souza, Almir Rodrigues Durigon

orienta-se pela busca da percepção que os gestores da UNEMAT têm sobre o papel da controladoria no alcance da eficácia institucional.

A justificativa e a contribuição dessa pesquisa baseiam-se, fundamentalmente, em dois âmbitos, o primeiro de ordem teórica e o segundo de ordem prática. Do ponto de vista teórico, contribui para que se conheça o papel da controladoria em IES pública, além de servir como referência a outros estudos correlatos, aumentando a massa de conhecimento, favorecendo futuras pesquisas com esse foco. Em termos práticos, oportuniza que se conheça, empiricamente, o papel da controladoria e proporciona a ampliação de reflexões sobre a sua função no âmbito da gestão de uma IES pública. Além disso, o estudo surge em complemento a diversos outros realizados sobre o tema, destacando-se Maynard e Stammerman, (1974), Pettersen e Solstad (2007), Dittadi (2008), Freire (2010) e Peleias et al. (2011).

Além desta introdução o estudo contempla outras quatro seções. A primeira delas corresponde à contextualização teórica do tema; na segunda, o destaque é dos principais aspectos metodológicos da pesquisa; a terceira concentra-se na apresentação, análise e discussão dos dados e resultados. Por fim, tem-se a conclusão do estudo, seguida da lista das referências utilizadas na sua elaboração.

\section{REFERENCIAL TEÓRICO}

\subsection{Gestão pública}

As discussões sobre a qualidade da gestão têm, historicamente, se reportado a modelos que potencialmente contribuem para melhores desempenhos. A esse respeito, Bresser-Pereira (1996) retoma as questões e características da administração pública burocrática, adotada para substituir a administração patrimonialista. Ainda segundo Bresser-Pereira, apesar da adoção da administração pública burocrática, a pressuposição de eficiência em que se pauta essa forma de administrar não se revelava real. 
Controladoria em Instituição pública de Ensino Superior: Percepção do seu papel sob a ótica dos

gestores

Marcos Antonio de Souza, Almir Rodrigues Durigon

Pacheco (2002) focaliza que a literatura brasileira sobre a administração pública tem sido marcada pela defesa da burocracia weberiana como solução para os problemas administrativos do país. Por outro lado, Fillippim, Rossetto e Rossetto (2010) explicam que a burocracia além de não conseguir superar o patrimonialismo tornou-se um fim em si mesma; e de outra parte, para eles, censurar a burocracia não significa deixar de reconhecer que ela representou um progresso em relação ao patrimonialismo, e que ainda continua contribuindo de forma importante para a gestão pública brasileira.

Nessa sequência de busca e desenvolvimento de novos modelos de gestão surge uma nova configuração denominada de Nova Gestão Pública, a qual, de acordo com Barzelay (2003) é um debate sobre a estrutura organizacional de gestão e controle da administração pública, buscando respostas relacionadas ao modo de estruturar, gerenciar e controlar os sistemas burocráticos públicos. Fidelis (2006) enfatiza que a Nova Gestão Pública (NGP) ou New Public Management (NPM), procura promover nas organizações públicas os modelos de gestão da iniciativa privada, bem como os conceitos de administração estratégica direcionada aos negócios empresariais e aos conceitos de empreendedorismo. Fillippim, Rossetto e Rossetto (2010) trazem uma visão integrada dos diversos modelos, e destacam que o patrimonialismo, a burocracia e a nova gestão pública não são separados e restritos a um único período de tempo. Para eles, essas são abordagens que ainda se cruzam na definição teórica e na prática da administração pública brasileira.

Dentre os vários instrumentos utilizados nessa busca de uma moderna e eficaz gestão pública, a controladoria tem sido reconhecida como uma atividade de papel relevante (SLOMSKI, 2005). Isso pode, naturalmente, ser encaminhado à gestão das IES públicas. O estudo de Peter et al. (2003) trata especificamente das contribuições que a controladoria, no contexto da NPM, pode trazer à gestão das IES públicas. Nesse sentido, os conceitos e as aplicações da NPM, contando com a participação da controladoria, podem contribuir com as políticas institucionais das universidades públicas, possibilitando encontrar respostas e soluções para os problemas relacionados com esses temas. 
Controladoria em Instituição pública de Ensino Superior: Percepção do seu papel sob a ótica dos

gestores

Marcos Antonio de Souza, Almir Rodrigues Durigon

\subsection{Caracterização geral da controladoria}

A Controladoria é uma área que apresenta um amplo campo de atuação dentro de uma organização devido a sua abrangência e a sua multidisciplinaridade, e por essa razão sua presença favorece o bom desempenho da entidade. Sustentando essa afirmação, Slomski (2005) afirma que a controladoria é a busca pelo alcance do ótimo resultado em qualquer ente, seja ele público ou privado.

Corroborando com esse entendimento, Beuren et al. (2007) relatam que a controladoria é destacada como a área que beneficia o processo de gestão, por meio de informações que dão base ao processo de tomada de decisão. Borinelli (2006, p. 5) apresenta uma compreensão mais ampliada e trata a controladoria como um "conjunto de doutrinas e conhecimentos, que se constituem em bases teóricas e conceituais de ordem operacional, econômica, financeira e patrimonial, relativas ao controle do processo de gestão organizacional".

Ao relacioná-la com a gestão organizacional, Sutthiwan e Clinton (2008) complementam que o papel da controladoria é fundamentalmente uma função de gestão que se preocupa com a melhora dos resultados. Apoiando essa concepção sobre o papel da controladoria, Benĉová e Kal'avská (2009) definem que ela é a responsável em fornecer informações para que a organização possa alcançar seus objetivos, pois permite aos gestores adaptar a organização às mudanças no ambiente, dado o processo de planejar e realizar todas as funções de coordenação que forem necessárias.

\subsection{Controladoria nas instituições públicas}

$\mathrm{Na}$ administração pública brasileira, a Lei 4.320/1964, a Constituição Federal de 1988 e a Lei de Responsabilidade Fiscal - LRF, 101/2000 mencionam em seus textos somente a palavra controle interno e não controladoria.

Conforme a Lei 4320/64, artigos 75 e 76, a execução de controle compreenderá a legalidade dos atos, a fidelidade funcional e o cumprimento do planejamento do trabalho, e que o Poder Executivo exercerá esses três tipos de controle mencionados. 
Em seguida, a Constituição Federal de 1988, nos artigos 70 e 74, reforça a exigência de controle, com objetivo de auxiliar os administradores na gestão contábil, financeira, operacional e patrimonial, determinando a criação de um sistema de controle interno como parte integrante da estrutura organizacional. Com o advento da LRF, o controle ganhou mais força, pois em seu artigo 59 ficou determinado que a fiscalização da gestão fosse realizada pelo Poder Legislativo com auxílio do Tribunal de Contas, além do Sistema de Controle Interno de cada poder e do Ministério Público.

Os termos controle e controladoria na maioria das vezes são tratados como sinônimos. No entanto, o uso do termo controle pode ser considerado inadequado uma vez que a controladoria tem uma área de abrangência mais ampla, sendo o controle interno considerado um dos seus instrumentos. Sobre o conceito de controle, Imoniana e Nohara (2005, p. 38) explicam que "controlar é um ato de orientar quanto ao caminho a ser trilhado para o cumprimento de tarefas definidas". Já Silva (2003) explica que controle está na presença de um único órgão de controle o qual é denominado de controladoria ou órgão de controle interno. Na concepção de Borinelli (2006) o controle está em relação à prática da controladoria, como uma das suas funções. Para o autor a controladoria se ocupa do processo de controle de gestão, e todas essas atividades estão relacionadas em proteger o interesse da organização bem como seu patrimônio. Essas ações fazem parte das funções de controladoria, e que o controle interno é uma dessas ações por meio das quais essa área de conhecimento se materializa dentro das organizações.

Diante dessa diferenciação entre controle e controladoria, compreende-se controle como parte da ação da controladoria, pois o controle auxilia na melhor utilização dos recursos, especialmente, como instrumento de defesa do patrimônio. A controladoria tem como finalidade acompanhar o cumprimento das metas previstas, bem como comprovar a legalidade e avaliar os resultados quanto à eficácia e eficiência da gestão.

$\mathrm{Na}$ administração pública, a controladoria, de acordo com Thompson e Jones (1986) é voltada, principalmente, ao acompanhamento da efetivação orçamentária. Já 
Controladoria em Instituição pública de Ensino Superior: Percepção do seu papel sob a ótica dos gestores

Marcos Antonio de Souza, Almir Rodrigues Durigon

Dupuis (2006) compreende que a controladoria moderna deve se preocupar, além do cumprimento do orçamento, com todos os aspectos da gestão do setor público. Considera ainda que outras funções gerenciais devam ser privilegiadas por essa área, tais como: alocação eficiente de recursos, auxílio na tomada de decisão eficaz, avaliação de desempenho e obtenção de resutados.

Apresentando a mesma compreensão, Slomski (2005) entende que a controladoria pública é a área responsável em gerenciar todo o sistema de informação, com o propósito de subsidiar os gestores na mensuração dos resultados. Peter et al. (2003) comungam dessa mesma ideia, ao afirmar que o papel da controladoria pública é avaliar a maneira como os resultados são atingidos no processo de gestão.

\subsection{Controladoria nas instituições públicas de ensino superior}

As IES públicas têm papel importante na formação da sociedade. Dada essa importância na formação social dos indivíduos, elas são cobradas quanto à eficiência e a eficácia da qualidade do ensino superior e a maneira como tem administrado os recursos públicos que estão a sua disposição. Sobre isso, Marra e Mello (2005) destacam que as universidades públicas têm sido questionadas pelo governo e pela sociedade em relação aos seus objetivos, da austeridade de sua estrutura burocrática, da ineficiência na gestão dos recursos e de pouca pertinência social dos serviços prestados.

A repercussão sobre a constante evolução da economia globalizada tem apresentado destaque nas discussões sobre gestão organizacional, cujos reflexos também ocorrem no âmbito da gestão pública. Matias-Pereira (2008), ao comentar sobre a globalização e o setor público, observa que no passado os teóricos da administração pública se preocupavam com os fenômenos administrativos no interior do país de sua atuação, porém, com o advento da globalização essa realidade trouxe para as discussões os problemas administrativos e as suas soluções em escala mundial. Para o autor a globalização foi responsável por diversas mudanças teóricas e práticas no setor público em todos os países. 
Controladoria em Instituição pública de Ensino Superior: Percepção do seu papel sob a ótica dos

gestores

Marcos Antonio de Souza, Almir Rodrigues Durigon

Nesse sentido, Nunes e Ferraz (2005) afirmam que nas últimas décadas tem havido um repensar na forma de inovação das IES públicas, preservando suas características institucionais e conseguindo, de forma mais eficaz, atender aos novos e crescentes desafios sociais, tornando-se mais produtiva e transparente à sociedade.

Machado (2005), no contexto de atuação da controladoria afirma que para as instituições de ensino superior atingirem os seus objetivos de formar alunos com competência e conhecimento, é necessário que criem meios que aceitem se ajustar ao ambiente com eficácia, eficiência e economicidade, pois as variáveis ambientais estão fora do controle do sistema de ensino, mas determinam em parte o funcionamento da instituição. Já para Ferreira (2001) as instituições de ensino superior devem apresentar resultados, e para isso precisam desenvolver instrumentos gerenciais que auxiliem os gestores no processo de tomada de decisão.

Conforme apresentado no estudo de Machado (2005), pode-se compreender a controladoria como uma área dentro da IES e que abrange a parte contábil, financeira e gerencial. Para Machado (2005) essa atuação busca assegurar melhor atendimento às necessidades de desenvolvimento da administração, bem como do setor acadêmico como um todo (alunos, professores, secretarias, laboratórios, divisão de graduação, pós-graduação, extensão etc.). Contribuindo para melhor compreensão de cada área que a controladoria abrange, Borinelli (2006) apresenta o detalhamento resumido no Quadro 1.

\begin{tabular}{|c|c|}
\hline Áreas & Definição \\
\hline Contábil & $\begin{array}{c}\text { É responsável em elaborar demonstrações contábeis, controle e análise } \\
\text { das contas a pagar, a receber, evolução do patrimônio, do } \\
\text { comprometimento da receita com a folha de pagamento. }\end{array}$ \\
\hline Financeira & $\begin{array}{c}\text { É responsável em administrar os recursos, prestar contas, e gerir os } \\
\text { investimentos. }\end{array}$ \\
\hline Gerencial & $\begin{array}{l}\text { É responsável pelo sistema de informação da organização, pela melhoria } \\
\text { contínua dos processos de negócios, além de acompanhar a distribuição e } \\
\text { execução do orçamento e do plano estratégico da organização. }\end{array}$ \\
\hline
\end{tabular}

Quadro 1 - Áreas de abrangência da controladoria Fonte: Borinelli (2006). 
Controladoria em Instituição pública de Ensino Superior: Percepção do seu papel sob a ótica dos

gestores

Marcos Antonio de Souza, Almir Rodrigues Durigon

Reforçando o papel da controladoria na gestão das IES públicas, Maynard e Stammerman (1974) compreendem que as funções da controladoria na gestão dessas instituições envolvem: (a) elaborar relatórios; (b) projetar cenários; (c) realizar projeções orçamentárias; (d) orientar os gestores para os melhores resultados. Abunahman e Zotez (2006) complementam que a controladoria quando implantada nas instituições de ensino superior possibilita melhorar com responsabilidade os atos praticados pela administração.

\subsection{Estudos relacionados}

Com base na revisão bibliográfica realizada, alguns estudos relacionados à gestão de IES foram encontrados. Apresentam-se a seguir aqueles mais diretamente relacionados ao objeto desta pesquisa.

\begin{tabular}{|c|c|c|}
\hline Obra & Título & Objetivos \\
\hline $\begin{array}{l}\text { Maynard e } \\
\text { Stammerman, } \\
(1974)\end{array}$ & $\begin{array}{l}\text { O papel do controller nas } \\
\text { instituições de ensino superior }\end{array}$ & $\begin{array}{l}\text { Investigar a percepção do controller de } \\
\text { seu papel nas IES e se essa percepção é } \\
\text { diferente da forma como os } \\
\text { administradores acadêmicos a concebem }\end{array}$ \\
\hline $\begin{array}{l}\text { Pettersen e } \\
\text { Solstad } \\
(2007)\end{array}$ & $\begin{array}{c}\text { O papel da informação contábil: um } \\
\text { estudo nas instituições de ensino } \\
\text { superior. }\end{array}$ & $\begin{array}{l}\text { Discutir sobre o papel dos orçamentos e } \\
\text { das informações nas IES, principalmente } \\
\text { sobre como as informações contábeis são } \\
\text { interpretadas e utilizadas pelos gestores } \\
\text { nas tomadas de decisão. }\end{array}$ \\
\hline $\begin{array}{l}\text { Dittadi } \\
(2008)\end{array}$ & $\begin{array}{c}\text { Práticas de controladoria adotadas } \\
\text { no processo de gestão de IES } \\
\text { estabelecidas no Estado de Santa } \\
\text { Catarina }\end{array}$ & $\begin{array}{l}\text { Investigar a utilização das práticas de } \\
\text { controladoria adotadas no processo de } \\
\text { gestão de IES catarinenses }\end{array}$ \\
\hline Freire (2010) & $\begin{array}{l}\text { A percepção de gestores de } \\
\text { universidades corporativas da } \\
\text { cidade de São Paulo sobre a } \\
\text { formação em controladoria como } \\
\text { competência para o alinhamento } \\
\text { do perfil dos gestores às } \\
\text { estratégias das organizações. }\end{array}$ & $\begin{array}{l}\text { Identificar e analisar a percepção dos } \\
\text { gestores que atuam nas universidades } \\
\text { corporativas na cidade de São Paulo } \\
\text { sobre o papel da controladoria no que diz } \\
\text { respeito à competência dos gestores e às } \\
\text { estratégias das organizações }\end{array}$ \\
\hline $\begin{array}{l}\text { Peleias et al. } \\
\quad(2011)\end{array}$ & $\begin{array}{l}\text { Adesão ao Prouni - extrato de } \\
\text { pesquisa sobre a percepção de } \\
\text { controllers em IES privadas da } \\
\text { cidade de São Paulo }\end{array}$ & $\begin{array}{l}\text { Identificar e analisar a percepção dos } \\
\text { controllers em IES privadas da cidade de } \\
\text { São Paulo }\end{array}$ \\
\hline
\end{tabular}

Quadro 2 - Estudos relacionados à controladoria e às IES

Fonte: Autores citados. 
Controladoria em Instituição pública de Ensino Superior: Percepção do seu papel sob a ótica dos gestores

Marcos Antonio de Souza, Almir Rodrigues Durigon

O estudo de Maynard e Stammerman (1974) concluiu que apesar de algumas divergências, há consenso geral quanto ao papel do controller nas IES. Pettersen e Solstad (2007) concluíram que há pouca utilização das informações contábeis, além da ausência de processo de controles nas organizações pesquisadas. Dittadi (2008) concluiu que existe afinidade na utilização de práticas de controladoria entre as IES comunitárias/confessionais/filantrópicas e públicas municipais.

Já a pesquisa de Freire (2010) ratificou os achados na revisão da literatura, evidenciando a percepção dos sujeitos entrevistados de que as universidades corporativas podem colaborar para o aperfeiçoamento das aptidões dos gestores quanto às noções de controladoria, diminuindo o espaço existente entre os cursos superiores ofertados pelas IES. E, Peleias et al. (2011) concluíram que a controladoria dessas instituições não tem ação operacional quanto aos fatos relativos ao PROUNI, o que diminui o provimento de informação para as tomadas de decisões relativas a este assunto.

\section{ASPECTOS METODOLÓGICOS}

\subsection{Classificação da pesquisa}

O estudo, devido à natureza do problema, caracteriza-se por uma abordagem predominantemente quantitativa, complementada pela análise qualitativa sobre 0 significado dos dados. Richardson (1999, p. 70) caracteriza a pesquisa quantitativa como "o emprego da quantificação tanto nas modalidades de coleta de informações, quanto no tratamento delas por meio de técnicas estatísticas". Sobre o emprego da pesquisa qualitativa, Richardson considera que essa metodologia pode "descrever a complexidade de determinado problema, analisar a interação de certas variáveis, compreender e classificar os processos dinâmicos vividos por grupos sociais".

Quanto ao objetivo, baseando-se em Collis e Hussey (2005) a pesquisa é classificada como descritiva por estar relacionada a descrever como os fenômenos de 
Controladoria em Instituição pública de Ensino Superior: Percepção do seu papel sob a ótica dos

gestores

Marcos Antonio de Souza, Almir Rodrigues Durigon

atuação prática se desenvolvem, proporcionando elementos que permitem responder o problema de pesquisa.

O estudo foi desenvolvido sob o formato de estudo de caso único, abrangendo a Universidade do Estado de Mato Grosso - UNEMAT, uma IES de direito público localizada na cidade de Cáceres (MT) e vinculada à Secretária de Estado de Ciência e Tecnologia.

Como forma de manter o rigor da pesquisa científica, foi desenvolvido um protocolo de estudo de caso a fim de formalizar a estruturação da pesquisa. Para Gil (2010, p.120) "não existe um modelo fixo para elaboração do protocolo, mas, recomenda-se que seja subdividido em partes". Seguindo as orientações de Yin (2010), o protocolo envolveu: (a) delineamento da visão geral do projeto; (b) procedimentos de campo para a realização da pesquisa; (c) questões de estudo de caso utilizadas de forma específica em que o pesquisador deve ter durante a coleta de dados; d) guia para relatório de estudo de caso, compreendendo apresentação das questões de pesquisa, procedimentos de coleta de dados, tratamento dos dados e as conclusões.

\subsection{Procedimentos de coleta de dados}

A pesquisa foi realizada com a participação de gestores da UNEMAT, envolvendo reitor, vice-reitor, pró-reitores, controller e os coordenadores de campi. A amostra contém um total de 20 gestores que responderam ao questionário na presença dos pesquisadores.

Os dados foram coletados por meio de questionário constituído de perguntas fechadas. $O$ instrumento de pesquisa foi aplicado a todos os gestores selecionados para o estudo no $4^{\circ}$ trimestre de 2011, no Campus Universitário de Cáceres, ocasião em que se expôs a natureza e os objetivos da pesquisa. Antes da aplicação o questionário foi submetido a um pré-teste realizado com um gestor administrativo de IES, além de dois pesquisadores do tema do estudo e que não integram a população selecionada. Nessa fase foram avaliadas a abrangência e a compreensão das questões, validando o instrumento após algumas adaptações. 
Controladoria em Instituição pública de Ensino Superior: Percepção do seu papel sob a ótica dos

gestores

Marcos Antonio de Souza, Almir Rodrigues Durigon

Para elaboração do questionário utilizou-se a escala tipo Likert de 5 pontos (discordo totalmente (1), concordo totalmente (5)) a fim de mensurar o grau de concordância ou discordância dos sujeitos que responderam o instrumento de pesquisa.

Além do questionário, foram realizadas pesquisas nos documentos internos da instituição: a portaria no 507/2000 que trata da implantação da controladoria na UNEMAT, o manual de controladoria da universidade, editado em 2001 e a resolução 015/2008 que apresenta a estrutura organizacional da instituição. Esses documentos foram utilizados para melhor entendimento e esclarecimento das atividades da instituição em geral e da controladoria em particular. Complementando o processo, observações diretas foram realizadas em alguns dos campos representados na pesquisa.

\subsection{Tratamento dos Dados}

Os dados da amostra foram tabulados de forma quantitativa, utilizando 0 programa MS-Excel como ferramenta para o procedimento estatístico descritivo, tais como o Ranking Médio (RM) dos fatores da escala.

Segundo Oliveira (2005), o Ranking Médio mensura o grau de concordância dos respondentes. Para uma escala de 5 pontos, os resultados menores que 3 são considerados como discordantes; maiores que 3 como concordantes; quando exatamente 3 é considerado indiferente. Os dados foram, na sequência, submetidos a uma análise de natureza qualitativa sobre os respectivos significados.

\section{APRESENTAÇÃO E ANÁLISE DOS DADOS}

\subsection{Caracterização geral da UNEMAT}

A UNEMAT é uma entidade autônoma de direito público, vinculada à Secretária de Estado de Ciência e Tecnologia do Estado do Mato Grosso, cujos objetivos fundamentais são o ensino, a pesquisa e a extensão. 
Controladoria em Instituição pública de Ensino Superior: Percepção do seu papel sob a ótica dos

Atualmente a UNEMAT se faz presente em 11 regiões, resguardando as múltiplas diversidades geográficas, econômicas e culturais do Estado. A universidade conta com total de 11 Campi Universitários, 15 Núcleos Pedagógicos, atende a 108 dos 141 municípios do Estado. O contingente educacional da UNEMAT é de aproximadamente 15 mil acadêmicos em seus cursos regulares, especialização Lato Sensu, especialização Stricto Sensu, educação indígena e educação à distância.

\subsection{Controladoria na UNEMAT}

A controladoria na UNEMAT teve sua implantação iniciada no ano $2000 \mathrm{com}$ a Portaria ํㅗ 507, por meio da qual a reitoria designou uma comissão responsável pela implantação da controladoria na universidade. Desse modo, atendendo à CF de 1988, artigos 70 e 74, e ao dispositivo legal previsto no Artigo 46 da Constituição do Estado de Mato Grosso, de 1989, a IES incorporou a controladoria à sua estrutura organizacional.

Conforme definido no Manual de Controladoria (UNEMAT, 2001), a controladoria na UNEMAT, assim como todas as áreas da instituição, deve se esforçar para garantir o cumprimento da missão e a continuidade da organização. Seu papel fundamental consiste em coordenar os esforços para conseguir um resultado global sinérgico, tendo como missão primordial a geração de informações relevantes para a tomada de decisão, no âmbito da universidade.

Estão definidas também neste manual, as funções básicas da controladoria no âmbito da UNEMAT, conforme descrito no Quadro 3. 
Controladoria em Instituição pública de Ensino Superior: Percepção do seu papel sob a ótica dos

gestores

Marcos Antonio de Souza, Almir Rodrigues Durigon

\begin{tabular}{|c|c|}
\hline Funções & Descrição \\
\hline Função informativa & $\begin{array}{r}\text { Compreende os sistemas contábeis e financeiros da universidade, sistema } \\
\text { de pagamento e recebimentos, folha de pagamento etc. }\end{array}$ \\
\hline Função motivação & $\begin{array}{r}\text { Refere-se aos efeitos dos sistemas de controle sobre o comportamento } \\
\text { das pessoas diretamente atingidas. }\end{array}$ \\
\hline Função coordenação & $\begin{array}{c}\text { Visando centralizar as informações com vistas à aceitação de planos sob } \\
\text { o ponto de vista econômico e à assessoria da direção da UNEMAT, não } \\
\text { somente alertando para situação desfavorável em alguma área, mas } \\
\text { também sugerindo soluções. }\end{array}$ \\
\hline Função planejamento & $\begin{array}{c}\text { Consiste em verificar se os planos são consistentes ou viáveis, e se } \\
\text { realmente poderão servir de base para uma avaliação posterior. }\end{array}$ \\
\hline $\begin{array}{c}\text { Função } \\
\text { acompanhamento }\end{array}$ & $\begin{array}{r}\text { Relativo a continua verificação da evolução dos planos para fins de } \\
\text { correção de falhas ou revisão do planejamento. }\end{array}$ \\
\hline
\end{tabular}

Quadro 3 - Funções básicas da controladoria da UNEMAT

Fonte: Unemat (2001).

Observa-se que as funções da controladoria, no âmbito da UNEMAT, estão direcionadas para o fortalecimento da organização, zela preventivamente pela regularidade financeira dos gastos públicos, pela fidelidade orçamentária dos projetos, exame da legalidade dos atos, contratos e convênios da administração.

\subsection{Perfil dos Gestores da UNEMAT}

Os gestores envolvidos na pesquisa dividem-se em dois grupos: a reitoria, composta por reitor, vice-reitor, pró-reitores e controller; e os coordenadores de campi, totalizando um número de 20 gestores. Apresenta-se na Tabela 10 perfil dos respondentes. 
Controladoria em Instituição pública de Ensino Superior: Percepção do seu papel sob a ótica dos gestores Marcos Antonio de Souza, Almir Rodrigues Durigon

Tabela 1 - Perfil dos gestores da UNEMAT

\begin{tabular}{|c|c|c|c|}
\hline Variável & Descrição & $\begin{array}{c}\text { Frequência } \\
\text { Absoluta }\end{array}$ & Frequência Relativa \\
\hline Gênero & Masculino & 14 & $70 \%$ \\
\hline \multirow{2}{*}{ Escolaridade } & Feminino & 6 & $30 \%$ \\
\hline & Mestre & 9 & $45 \%$ \\
& Doutor & 9 & $45 \%$ \\
\hline Tempo de experiência & Especialista & 2 & $10 \%$ \\
\hline & De 1 ano até 5 anos & 3 & $15 \%$ \\
\hline & Mais de 10 anos & 9 & $45 \%$ \\
\hline \multirow{2}{*}{ Cargo ocupado } & Reitor & 8 & $40 \%$ \\
\hline & Vice-reitor & 1 & $5 \%$ \\
\hline & Controller & 1 & $5 \%$ \\
\hline & Pró-reitor & 6 & $5 \%$ \\
\hline & Coordenador de campi & 11 & $30 \%$ \\
\hline
\end{tabular}

Fonte: Dados da Pesquisa

Como esperado, os dados da Tabela 1 evidenciam que a maioria dos respondentes apresenta formação em nível de mestrado e doutorado. Constata-se que do total de pessoas respondentes, o maior número é de coordenadores de campi, a maioria deles atuando em campi longe da sede da IES, localizada em Cáceres-MT. Outra constatação é a alta incidência de gestores com largo tempo de atuação na instituição.

\subsection{Percepções sobre as mudanças conceituais da gestão pública}

$\mathrm{O}$ primeiro bloco de questões (Tabela 2) tratadas pela pesquisa refere-se à percepção dos gestores quanto às mudanças conceituais sobre a gestão pública.

Os resultados obtidos estão descritos nas colunas de Ranking Médio (RM) dos fatores da escala. Na coluna Reitoria e C. de Campi tem-se a percepção de todos os gestores: reitor, vice-reitor, controller, pró-reitores e coordenadores de campi. A coluna reitoria compreende a percepção apenas dos ocupantes da reitoria: reitor, vice-reitor, controller e pró-reitores. A coluna C. Campi corresponde ao posicionamento dos coordenadores de campi. Essa estrutura se mantém nas tabelas seguintes. 
Controladoria em Instituição pública de Ensino Superior: Percepção do seu papel sob a ótica dos

gestores

Marcos Antonio de Souza, Almir Rodrigues Durigon

Tabela 2 - Mudanças conceituais sobre a gestão pública

\begin{tabular}{|c|c|c|c|}
\hline Descrição & $\begin{array}{l}\text { RM } \\
\text { Reitoria e } \\
\text { C. Campi }\end{array}$ & $\begin{array}{l}\text { RM } \\
\text { Reitori } \\
\text { a }\end{array}$ & $\begin{array}{l}\text { RM } \\
\text { C. } \\
\text { Campi }\end{array}$ \\
\hline $\begin{array}{c}\text { New Public Management - NPM são práticas gerencias que se } \\
\text { forem adotadas no Brasil modificarão a forma dos gestores } \\
\text { tomarem as decisões. }\end{array}$ & 3,60 & 4,11 & 3,18 \\
\hline $\begin{array}{l}\text { A gestão pública ainda é voltada para o cumprimento do que foi } \\
\text { orçado. }\end{array}$ & 3,95 & 3,78 & 4,09 \\
\hline $\begin{array}{c}\text { O novo plano de contas aplicado ao setor público é obrigatório a } \\
\text { partir de } 2013 \text { deixará a contabilidade pública mais útil conforme } \\
\text { a contabilidade privada. }\end{array}$ & 4,00 & 4,44 & 3,64 \\
\hline $\begin{array}{l}\text { 4. A mensuração da eficiência do uso de recursos públicos esta } \\
\text { relacionada à forma pela qual os recursos são consumidos e } \\
\text { controlados. }\end{array}$ & 4,25 & 4,11 & 4,36 \\
\hline $\begin{array}{l}\text { A eficácia esta relacionada ao atingimento dos objetivos e das } \\
\text { metas. }\end{array}$ & 4,50 & 4,67 & 4,36 \\
\hline $\begin{array}{l}\text { Os gestores da instituição conhecem e estão comprometidos com } \\
\text { os princípios da Nova Gestão Pública - NGP. }\end{array}$ & 3,65 & 4,00 & 3,36 \\
\hline $\begin{array}{l}\text { A alta direção da instituição esta efetivamente comprometida com } \\
\text { a disponibilização dos recursos necessários à adoção do novo } \\
\text { plano de contas e sistemas de custos da contabilidade pública. }\end{array}$ & 3,90 & 3,89 & 3,91 \\
\hline Ranking Médio Geral & 3,97 & 4,14 & 3,84 \\
\hline
\end{tabular}

Fonte: Dados da pesquisa.

Identifica-se, de modo geral, que os gestores, tanto da reitoria quanto dos coordenadores de campi aprovam as mudanças conceituais sobre gestão pública, dando a devida importância a essas modificações. Destaca-se um grau de concordância considerado elevado no RM total da reitoria, acima de 4. Assim, para os respondentes, as mudanças favorecem o direcionamento a uma gestão pública eficaz.

Esse resultado ratifica os de outras pesquisas, como de Gonçalves (2003) no Mato Grosso do Sul, e de Silva e Fadul (2011) com gestores públicos do estado da Bahia.

\subsection{Percepções sobre a estrutura material e humana da controladoria}

Este segundo bloco de questões (Tabela 3) se refere à percepção dos gestores da UNEMAT quanto à estrutura física e humana atual da área de controladoria. 
Controladoria em Instituição pública de Ensino Superior: Percepção do seu papel sob a ótica dos

gestores

Marcos Antonio de Souza, Almir Rodrigues Durigon

Tabela 3 - Estrutura material e humana da controladoria

\begin{tabular}{|c|c|c|c|}
\hline Descrição & $\begin{array}{c}\text { RM } \\
\text { Reitoria e } \\
\text { C. Campi }\end{array}$ & $\begin{array}{c}\text { RM } \\
\text { Reitoria }\end{array}$ & $\begin{array}{c}\text { RM } \\
\text { C. } \\
\text { Campi }\end{array}$ \\
\hline $\begin{array}{l}\text { O corpo de funcionários é suficiente para atender as necessidades } \\
\text { funcionais da controladoria. }\end{array}$ & 1,75 & 1,78 & 2,09 \\
\hline $\begin{array}{l}\text { O sucesso de um sistema de informações depende do pessoal que } \\
\text { o alimenta e o faz funcionar. }\end{array}$ & 4,00 & 3,56 & 4,36 \\
\hline A controladoria conta com espaço e instalações físicas adequadas. & 2,70 & 2,78 & 2,64 \\
\hline $\begin{array}{l}\text { 11. Os funcionários possuem habilidades suficientes para uso de } \\
\text { recursos de tecnologia de informação. }\end{array}$ & 3,70 & 3,89 & 3,55 \\
\hline $\begin{array}{l}\text { 12. Os funcionários são constantemente submetidos a cursos de } \\
\text { reciclagem e aperfeiçoamento. }\end{array}$ & 3,85 & 4,22 & 3,55 \\
\hline $\begin{array}{l}\text { 13. A controladoria não possui estrutura de informática (hardware e } \\
\text { software) suficiente para o bem executar suas atividades. }\end{array}$ & 3,30 & 3,78 & 2,82 \\
\hline Ranking Médio Geral & 3,21 & 3,33 & 3,16 \\
\hline
\end{tabular}

Fonte: Dados da Pesquisa.

Os dados revelam que a opinião dos respondentes em relação ao corpo de funcionários para atender as necessidades funcionais da controladoria é discordante numa dimensão elevada, apresentando um RM da Reitoria e dos Coordenadores de Campi de 1,75 , ou seja, consideram insuficiente para atender as necessidades funcionais do setor.

Sobre o espaço físico e as instalações do setor de controladoria as opiniões também são discordantes numa escala mediana, alcançando um RM da Reitoria e dos Coordenadores de Campi 2,70. Todos os gestores avaliam que o espaço físico e as instalações são inadequadas para as necessidades funcionais da controladoria.

No que se refere à estrutura de informática, o RM Reitoria e C. de Campi situa-se em 3,78, uma diferença substancial em relação aos 2,82 dos coordenadores de Campi. Dada essa diferença, esse é um elemento que enseja uma abordagem mais específica sobre as suas causas.

De acordo com o RM Total de 3,21 pontos, na escala de 5, fica evidente que os gestores da instituição, tanto os da reitoria quanto os de campi avaliam que o cumprimento do papel da controladoria fica parcialmente comprometido devido aos ajustes necessários no que se refere à sua estrutura material e humana. 
Controladoria em Instituição pública de Ensino Superior: Percepção do seu papel sob a ótica dos

gestores

Marcos Antonio de Souza, Almir Rodrigues Durigon

\subsection{Percepções sobre a ligação organizacional do controller e da controladoria}

O terceiro bloco de questões (Tabela 4) trata do posicionamento do controller, da controladoria e satisfação com as atividades do setor. A primeira afirmativa apresenta um número de indecisos (não concordo - nem discordo) que está em relação aos respondentes da reitoria. Nota-se que em relação ao RM C. de Campi há uma concordância reduzida com RM de 3,27. Assim como outras afirmativas, parece haver um desconhecimento significativo quanto a posição organizacional do controller e da controladoria na IES.

A opinião da reitoria é discordante numa dimensão mediana, quando a afirmativa se refere que o responsável pela controladoria responde diretamente ao pró-reitor de administração. O RM Reitoria corresponde 2,56, considerando que o responsável pela controladoria não responde diretamente ao pró-reitor de administração.

Tabela 4 - Posicionamento do controller e da controladoria

\begin{tabular}{|c|c|c|c|}
\hline Descrição & $\begin{array}{c}\mathbf{R M} \\
\text { Reitoria } \\
\text { e C. } \\
\text { Campi }\end{array}$ & $\begin{array}{c}\mathbf{R M} \\
\text { Reitori } \\
\text { a }\end{array}$ & $\begin{array}{c}\mathbf{R M} \\
\mathbf{C} . \\
\text { Campi }\end{array}$ \\
\hline $\begin{array}{c}\text { 14. O responsável pela controladoria responde diretamente ao } \\
\text { conselho universitário. }\end{array}$ & 3,15 & 3,00 & 3,27 \\
\hline $\begin{array}{c}\text { O responsável pela controladoria responde diretamente ao reitor da } \\
\text { UNEMAT. }\end{array}$ & 3,70 & 3,89 & 3,82 \\
\hline $\begin{array}{c}\text { 16. O responsável pela controladoria responde diretamente ao pró- } \\
\text { reitor de administração. }\end{array}$ & 3,20 & 2,56 & 3,45 \\
\hline $\begin{array}{c}\text { A controladoria é reconhecida pela alta e média direção como uma } \\
\text { atividade relevante ao alcance da eficácia institucional. }\end{array}$ & 3,85 & 4,00 & 3,73 \\
\hline $\begin{array}{c}\text { Os gestores estão satisfeitos com o suporte dado pela controladoria } \\
\text { para a boa realização das suas atividades. }\end{array}$ & 3,50 & 4,00 & 3,09 \\
\hline Ranking Médio Geral & $\mathbf{3 , 4 8}$ & $\mathbf{3 , 4 9}$ & $\mathbf{3 , 4 7}$ \\
\hline
\end{tabular}

Fonte: Dados da pesquisa.

No geral as demais assertivas mantêm uma concordância bastante reduzida, não atingindo o RM de 4 num máximo de 5. Quanto ao nível de satisfação com a controladoria, é flagrante a maior dimensão dada pela reitoria. Este também sinaliza a 
Controladoria em Instituição pública de Ensino Superior: Percepção do seu papel sob a ótica dos gestores Marcos Antonio de Souza, Almir Rodrigues Durigon

necessidade de estudos específicos sobre as razões da insatisfação dos coordenadores de campi.

\subsection{Percepções dos gestores sobre atuações específicas da controladoria}

Os próximos blocos de questões (Tabelas 5, 6 e 7) tratam da percepção dos gestores sobre o papel da controladoria na UNEMAT. Foi feita a divisão em três tabelas para melhor visualizar e explanar o papel da controladoria referente ao orçamento, à gestão financeira e à avaliação de resultados, e ao controle gerencial.

Destaca-se na Tabela 5 a elaboração de orçamentos e projeção de cenário. A reitoria se mostra discordante numa dimensão mediana com um RM de 2,56. Para os gestores da reitoria a controladoria não auxilia na elaboração de projeção de cenário.

Tabela 5 - Papel da controladoria na elaboração de orçamentos

\begin{tabular}{|c|c|c|c|}
\hline Descrição & $\begin{array}{c}\text { RM } \\
\text { Reitoria } \\
\text { e C. } \\
\text { Campi }\end{array}$ & $\begin{array}{c}\text { RM } \\
\text { Reitoria }\end{array}$ & $\begin{array}{c}\text { RM } \\
\text { C. } \\
\text { Campi }\end{array}$ \\
\hline $\begin{array}{l}\text { 19. Participa na elaboração do orçamento gerencial em } \\
\text { consonância com o planejamento da UNEMAT. }\end{array}$ & 3,45 & 3,67 & 3,27 \\
\hline $\begin{array}{l}\text { 20. Disponibiliza informações que subsidiem a elaboração do } \\
\text { orçamento. }\end{array}$ & 3,50 & 3,78 & 3,27 \\
\hline 21. Elabora projeção de cenário. & 3,10 & 2,56 & 3,55 \\
\hline Ranking Médio Geral & 3,35 & 3,33 & 3,36 \\
\hline
\end{tabular}

Fonte: Dados da pesquisa.

Os dados da Tabela 5 registram baixa concordância quanto à função da controladoria na instituição. As respostas sinalizam que há espaço acentuado para avanços da controladoria nesse aspecto orçamentário. O RM geral muito próximo a 3 indica uma posição de neutralidade, ou seja, não se identifica uma efetiva contribuição da controladoria.

$\mathrm{Na}$ Tabela 6 tem-se os dados referentes à participação da controladoria na gestão financeira e de resultados. No geral, os componentes da Reitoria apresentam percepção mais positiva quanto à atuação da controladoria nesses aspectos. A 
Controladoria em Instituição pública de Ensino Superior: Percepção do seu papel sob a ótica dos

gestores

Marcos Antonio de Souza, Almir Rodrigues Durigon

exemplo de outras questões discutidas parece haver um distanciamento entre a atuação da controladoria e dos gestores de campi. Este pode ser um direcionamento a que o controller procure se aproximar com esses gestores operacionais, visando clarear e superar as sinalizações desfavoráveis, pelo menos sob a ótica dos respondentes.

Tabela 6 - Papel da controladoria na gestão financeira e avaliação de resultados

\begin{tabular}{|c|c|c|c|}
\hline \multicolumn{1}{|c|}{ Descrição } & $\begin{array}{c}\text { RM } \\
\text { Reitoria } \\
\text { e C. } \\
\text { Campi }\end{array}$ & $\begin{array}{c}\text { RM } \\
\text { Reitoria }\end{array}$ & $\begin{array}{c}\text { RM } \\
\text { C. } \\
\text { Campi }\end{array}$ \\
\hline $\begin{array}{c}\text { 2. Avalia o desempenho da instituição com objetivo de contribuir } \\
\text { para a superação dos obstáculos para o alcance das metas } \\
\text { estabelecidas. }\end{array}$ & 4,05 & 4,22 & 3,91 \\
\hline $\begin{array}{c}\text { A atuação da controladoria tem levado aos gestores informações } \\
\text { e instrumentos que viabilizam alcançar a eficácia institucional. }\end{array}$ & 3,90 & 4,00 & 3,82 \\
\hline 24. Gerencia o sistema de custos. & 3,15 & 3,00 & 3,27 \\
\hline 25. Gerencia as despesas operacionais. & 3,40 & 3,56 & 3,27 \\
\hline 26. Efetua análise financeira pré e pós-realização das operações. & 3,20 & 3,33 & 3,09 \\
\hline 27. Possibilita ao gestor medir o impacto das decisões antes de \\
serem tomadas. & 3,40 & 3,67 & 3,18 \\
\hline Rossibilita melhor avaliação do desempenho da gestão pública. & 3,95 & 4,22 & 3,73 \\
\hline Ranking Médio Geral & $\mathbf{3 , 5 7}$ & $\mathbf{3 , 7 1}$ & $\mathbf{3 , 4 6}$ \\
\hline
\end{tabular}

Fonte: Dados da pesquisa.

De modo geral, os dados da Tabela 6 demonstram que é forte a concordância quanto ao reduzido nível do RM Total de cada coluna (RM Reitoria e C. Campi 3,57, RM Reitoria 3,71 e RM C. Campi 3,46) em relação a todas as questões desse bloco.

As afirmativas quanto à avaliação do desempenho da instituição, a atuação da controladoria no fornecimento de informações e avaliação do desempenho da gestão pública atingem uma expressiva concordância com um RM Reitoria. Tal resultado implica deduzir que os gestores concebem a controladoria como um órgão da reitoria que auxilia os gestores na obtenção de uma gestão financeira e avaliação de resultados satisfatórios. De qualquer forma, há que se observar diversas avaliações próximas da escala 3, apenas intermediária. 
Controladoria em Instituição pública de Ensino Superior: Percepção do seu papel sob a ótica dos

gestores

Marcos Antonio de Souza, Almir Rodrigues Durigon

Por fim, tem-se o último bloco de questões direcionadas a investigar o papel da controladoria na UNEMAT, agora em relação ao controle gerencial.

Tabela 7 - Papel da controladoria no controle gerencial

\begin{tabular}{|c|c|c|c|}
\hline Descrição & $\begin{array}{c}\text { RM } \\
\text { Reitoria } \\
\text { e C. } \\
\text { Campi } \\
\end{array}$ & $\begin{array}{c}\text { RM } \\
\text { Reitoria }\end{array}$ & $\begin{array}{l}\text { RM } \\
\text { C. } \\
\text { Campi }\end{array}$ \\
\hline $\begin{array}{l}\text { 9. Atua na identificação e controle dos elementos patrimoniais que } \\
\text { estão sujeito à risco. }\end{array}$ & 4,20 & 4,33 & 4,09 \\
\hline $\begin{array}{l}\text { 30. A controladoria não atua somente em sintonia com a obrigação } \\
\text { legal de controle, mas também nas funções de suporte ao processo } \\
\text { de gestão (planejamento, execução e controle). }\end{array}$ & 3,85 & 3,78 & 3,82 \\
\hline $\begin{array}{l}\text { 31. A controladoria participa ativamente no estabelecimento das } \\
\text { normas de procedimento e de controle interno da instituição. }\end{array}$ & 3,60 & 3,89 & 3,36 \\
\hline Ranking Médio Geral & 3,88 & 4,00 & 3,75 \\
\hline
\end{tabular}

Fonte: Dados da pesquisa.

Os dados da Tabela 7 indicam que a controladoria é parcialmente atuante no que se refere ao controle gerencial, no suporte ao processo de gestão e no estabelecimento de normas no controle interno da instituição, atingindo pontos de RM total de 3,88 (RM Reitoria e C. Campi), 4,00 (RM Reitoria) e 3,75 (RM C. Campi) o que caracteriza uma dimensão mediana. Há um entendimento relativo de que a controladoria ao atuar na identificação de um controle gerencial possibilita uma transformação comportamental da organização, visando à eficiência da instituição, mas que espaço para maiores avanços ainda persistem.

Somente na afirmativa sobre a atuação da controladoria na identificação e controle dos elementos patrimoniais que estão sujeito à risco é que os pontos na escala ficaram acima de 4,00. Isso pode ser considerado uma concordância expressiva em relação ao funcionamento da controladoria na instituição.

Durante a aplicação do instrumento de pesquisa, observou-se que as funções desempenhadas pela controladoria da UNEMAT ainda está em fase de desenvolvimento e que suas funções gerenciais estão sendo desempenhadas parcialmente. 
Controladoria em Instituição pública de Ensino Superior: Percepção do seu papel sob a ótica dos

gestores

Marcos Antonio de Souza, Almir Rodrigues Durigon

Os dados analisados indicam que apesar de serem em sua maioria concordantes e em forma positiva, há ainda uma necessidade de se conhecer melhor a aplicabilidade da controladoria no que diz respeito às suas funções dentro da instituição.

\section{CONCLUSÃO}

Nesse estudo procurou-se investigar como os gestores de uma IES pública percebem o papel da controladoria na eficácia institucional. Para tanto, foi selecionada para a realização da pesquisa a Universidade do Estado de Mato Grosso - UNEMAT, uma instituição de natureza pública e autônoma e que tem representação relevante no desenvolvimento econômico e social para o Estado de Mato Grosso.

Os resultados da pesquisa permitem afirmar que os gestores da UNEMAT têm um entendimento favorável ao papel da controladoria como uma área que contribui para o fortalecimento e desenvolvimento da instituição. Destaque-se, entretanto, que a análise dos dados demonstra que é preciso se conhecer melhor a aplicabilidade da controladoria dentro da instituição, assim como maior avanço na sua atuação gerencial.

A estrutura física e humana foi um dos aspectos com discordância mais elevada. Devido à controladoria ser um órgão que atua dentro da reitoria e contar com apenas um funcionário específico, seu desenvolvimento com eficácia fica comprometido pela falta de uma estrutura mais robusta.

A pesquisa revela que os gestores reconhecem que a controladoria pode auxiliar na projeção de cenários e elaboração do orçamento, mas precisa de uma maior atuação nesses processos. Isso pode ser constatado pelo reduzido grau de concordância apresentado.

Em síntese, considera-se que os resultados obtidos permitem observar que 0 papel da controladoria, no alcance da eficácia institucional na UNEMAT, tem-se demonstrado suficiente para 0 andamento da instituição, mas há necessidade de maiores esclarecimentos sobre essa função para uma organização pública. Acredita-se 
Controladoria em Instituição pública de Ensino Superior: Percepção do seu papel sob a ótica dos

gestores

Marcos Antonio de Souza, Almir Rodrigues Durigon

que os resultados da pesquisa podem ser importantes subsídios e contribuem para o aprimoramento da controladoria na instituição de ensino superior em estudo.

Entrevistas complementares com os gestores da reitoria sinalizam um contexto de maior preocupação com o profissionalismo da gestão pública, além da tradicional função de controle de uso das verbas destinadas. A rigor, as respostas indicam que é justamente no aspecto da gestão pela eficácia de resultados que há mais espaços para melhorias. $\mathrm{E}$ isso parece ser mais presente na ótica dos coordenadores de campi. Visualiza-se aqui o potencial para futuros estudos nessa temática, agora mais focada nesses coordenadores.

\section{REFERÊNCIAS}

ABUNAHMAN, José Geraldo; ZOTEZ, Luis Perez. (2006). Controle interno na administração pública federal: estudo do modelo de prestação de contas na Universidade Federal Fluminense. Boletim Técnico Organização \& Estratégia, v. 2, n. 2, p. 271-288.

BARZELAY, Michael. (2004). Introduction the process dynamics of public management policymaking. International Public Management Journal, v. 6, n. 3, p. 251-281.

BENĈOVÁ, M.; KAL'AVSKÁ, A. (2009). Importance of the controllership for the company performance software company experience. Ekonomie a Management, v. 2, p. 76-83.

BEUREN, Ilse M.; PASQUAL, Dino L.; SCHLINDWEIN, Antônio C. (2007). Abordagem da controladoria em trabalhos publicados no ENANPAD e no Congresso USP de Controladoria e Contabilidade de 2001 a 2006. Revista Contabilidade e Finanças, v. 18, n. 45, p. $22-37$.

BORINELLI, M. (2006). Estrutura conceitual básica de controladoria: sistematização à luz da teoria e da práxis. (Tese de Doutorado). Programa de Pós-Graduação em Ciências Contábeis. Universidade de São Paulo. São Paulo.

BRASIL. Lei 4320 de 17 de março de 1964. Estatui Normas Gerais de Direito Financeiro para elaboração e controle dos orçamentos e balanços da União, dos Estados, dos Municípios e do Distrito Federal. Brasília. Disponível em: <www.planalto.gov.br/ccivil_03/Leis/L4320. htm>. Acesso em: 19/jul/2011. 
Controladoria em Instituição pública de Ensino Superior: Percepção do seu papel sob a ótica dos

gestores

Marcos Antonio de Souza, Almir Rodrigues Durigon

BRASIL. Constituição de 1988. Constituição da República Federativa do Brasil de 1988. Brasília. Disponível em: <www.planalto.gov.br/ccivil_03/constituicao/constituiçao.htm>. Acesso em: 19/jul/2011.

BRASIL. Lei Complementar 101 de 4 de maio de 2000. Estabelece normas de finanças públicas voltadas para a responsabilidade na gestão fiscal. Brasília. Disponível em: <www.planalto.gov.br/ccivil_03/Leis/.../Lcp101.htm>. Acesso em 19/jul/2011.

BRESSER-PEREIRA, Luiz Carlos. (1996). Da administração pública burocrática a gerencial. Revista do Serviço Público, v. 47, n.1, p. 1-28.

COLLIS, Jill; HUSSEY, Roger. (2005). Pesquisa em administração: um guia prático para alunos de graduação e pós-graduação. (2 ed.). Porto Alegre: Bookman.

DITTADI, Jadir R. (2008). Práticas de controladoria adotadas no processo de gestão de instituições de ensino superior estabelecidas no Estado de Santa Catarina. (Dissertação de Mestrado). PPG em Ciências Contábeis da Unisinos. São Leopoldo.

DUPUIS, Jean. (2006). Modern controllership and the management accountability framework. Canadá. Disponível em: <http://www.parl.gc.ca/Content/LOP/researchpublications/ prb0623-e.html>. Acesso em: 17/jan/2011.

FERREIRA, Leonardo Nunes. (2001). Controladoria e modelo de gestão aplicada às instituições de ensino superior. (Dissertação de Mestrado). PPG em Gestão Empresarial. Escola Brasileira de Administração Pública da FGV. Rio de Janeiro.

FIDELIS, Jussara. (2006). Instrumentos de planejamento e suas contribuições na gestão municipal: estudo de caso em três municípios. (Dissertação de Mestrado). Pontifícia Universidade Católica do Paraná. Curitiba.

FILLIPIN, Eliane S.; ROSSETTO, Adriana M.; ROSSETTO, Carlos R. (2010). Abordagens da administração pública e sua relação com o desenvolvimento em um contexto regional: o caso do Meio Oeste Catarinense. Cadernos EBAPE. BR, v.8, n.4, p. 734-752.

FREIRE, Derneval Gondim. (2010). A percepção de gestores de universidades corporativas da cidade de São Paulo sobre a formação em controladoria como competência para 0 alinhamento do perfil dos gestores às estratégias das organizações. 2010. (Dissertação de Mestrado). PPG em Ciências Contábeis da FECAP. São Paulo. 
Controladoria em Instituição pública de Ensino Superior: Percepção do seu papel sob a ótica dos

gestores

Marcos Antonio de Souza, Almir Rodrigues Durigon

GIL, Antonio Carlos. (2010). Como elaborar projetos de pesquisa. (5 ed.). São Paulo: Atlas.

GONÇALVES, Eliane J. A. (2003). Mato Grosso do Sul - uma percepção da administração pública. Revista Eletrônica de Ciências Administrativa (RECADM), v. 1, n. 2, p. 1-13.

GUIMARÃES, Iolanda C.; PARISI, Claudio; PEREIRA, Anísio C.; WEFFORT, Elionor F. J. (2009). A importância da controladoria na gestão de riscos das empresas não financeiras: um estudo da percepção de gestores de riscos e controllers. RBGN, v.11, n.32, p. 260-275.

HOOD, Chistopher; PETERS, Guy. (2004). The middle aging of new public management: into the age of paradox? Journal of Public Administration Research and Theory, v.14, n.3, p. 267-282.

IMONIANA, Joshua Onome; NOHARA, Jouliana Jordan. (2005). Cognição da Estrutura de Controle Interno: Uma pesquisa exploratória. Base Unisinos, v. 2, n. 1, p. 37-46.

ISMAIL, Noor Azizi. (2010). Activity - basead management system implementation in higher education institution benefits and challengs. Emerald Group Publishing Limited, v. 27 , n. 1 , p. $40-52$.

LIMA, Fernando Barros; LUCA, Márcia M. Mendes; SANTOS, Sandra Maria; PONTE, Vera Maria Rodrigues. (2011). A controladoria em instituições financeiras: estudo de caso no Banco do Nordeste do Brasil S.A. Revista Contabilidade Vista \& Revista, v. 22, n. 1 , p. 43-72.

LINNA, Paula; PEKKOLA, Juhani; UKKO, Juhani; MELKAS, Helina. (2010). Defining and measuring productivity in the public sector: managerial perception. International Journal of Public Sector Management, v. 23, n. 3, p. 300-320.

MACHADO, Lucio de Souza. (2005). A controladoria no processo de gestão de instituições privadas de ensino superior de Goiás: um estudo sob a ótica de Contabilidade e finanças. (Dissertação de Mestrado). Programa de Pós-Graduação em Ciências Contábeis do Centro Universitário Álvares Penteado, São Paulo.

MARRA, Adriana V.; MELO, Marlene C. O. L. (2005). A prática social de gerentes universitários em uma instituição pública. Revista Administração Contemporânea, v. 9, n.3, p. 9-31.

MATIAS-PEREIRA, José. (2008). Administração pública comparada: uma avaliação das reformas administrativas do Brasil, EUA e União Europeia. RAP, v.42, n. 1, p. 61-82. 
Controladoria em Instituição pública de Ensino Superior: Percepção do seu papel sob a ótica dos

gestores

Marcos Antonio de Souza, Almir Rodrigues Durigon

MATO GROSSO. Constituição de 1989. (2012). Constituição do Estado de Mato Grosso de 1989. Cuiabá. Disponível em: <www.al.mt.gov.br/v2008/doc/constituicaomt.pdf>. Acesso em: 03/jan.

MAYNARD, Diane; STAMMERMAN James. (1974). An investigation into the role of the controller in institutions of higher education. Research in Higher Education, v. 2, p. 165171.

NUNES, S. C; FERRAZ, H. M. (2005). A reforma do ensino no Brasil e a inserção da noção de competências: um estudo empírico em instituições de educação superior. In: ENCONTRO ANUAL DA ANPAD, 29. 2005, Brasília. Anais... Brasília.

OLIVEIRA, Luciel Henrique. (2005). Exemplo de cálculo de ranking médio para Likert. Notas de Aula. Metodologia Científica e Técnicas de Pesquisa em Administração. (Dissertação de Mestrado). PPGA CNEC/FACECA: Varginha.

PACHECO, R. S. (2002). Escolas de governo como centros de excelência em gestão pública: a perspectiva da ENAP - Brasil. Revista do Serviço Público, v. 53, n. 1, p. 77 90 .

PELEIAS, Ivam Ricardo; STIEG, Carlos Maciel; BENEDICTO, Samuel Carvalho; BENEDICTO, Gideon Carvalho. (2011). Adesão ao Prouni - extrato de pesquisa sobre a percepção de Controllers em IES privadas da cidade de São Paulo. In: Congresso USP de Controladoria e Contabilidades, 11, 2011, São Paulo. Anais... São Paulo.

PETTERSEN, Inger - Johanne; SOLSTAD, Elsa. (2007). The role of accounting information in reforming area: a study of higher education institutions. Journal Compilaton, v. 23, n. 2, p. 133-154.

PETER, M. G. A.; CAVALCANTE, M. C. N.; PESSOA, M. N. M.; SANTOS, S. M.; PETER, F. A. (2003). A controladoria e a gestão pública: experiência do governo do estado do Ceará. In: Congresso del Instituto Internacional de Costos, 8. 2003. Anais... Punta de Leste.

RICHARDSON, Roberto J. (1999). Pesquisa Social: métodos e técnicas. São Paulo: Atlas.

SECCHI, Leonardo. (2009). Modelos organizacionais e reformas da administração pública. Revista de Administração Pública, v. 43, n. 2, p. 347-369.

SILVA, Lino Martins. (2003). Contabilidade Governamental. São Paulo: Atlas. 
Controladoria em Instituição pública de Ensino Superior: Percepção do seu papel sob a ótica dos

gestores

Marcos Antonio de Souza, Almir Rodrigues Durigon

SILVA, Lindomar Pinto; FADUL, Élvia. (2011). The cultural values of public managers of Bahia: a comparative analysis between Bahia and developed and developing countries. Business Management Dynamics, v. 1, n. 1, p. 107-121.

SLOMSKI, Valmor. (2005). Controladoria e governança na gestão pública. São Paulo: Atlas.

SUTTHIWAN, Angela, CLINTON, Douglas. (2008). The conflicting roles of controllership and compliance. Strategic Finance, v. 1, n. 1, p. 43-49.

UNIVERSIDADE DO ESTADO DE MATO GROSSO - UNEMAT. Portaria $n^{\circ}$ 507, de 27 de outubro de 2000. Comissão de implantação da controladoria na UNEMAT. Cáceres, 2000.

UNIVERSIDADE DO ESTADO DE MATO GROSSO - UNEMAT. Manual de Controladoria. Cáceres, 2001.

UNIVERSIDADE DO ESTADO DE MATO GROSSO - UNEMAT. Resolução RE $n^{\circ}$ 15, de 10 de julho de 2008. Aprova a Estrutura Organizacional da Universidade do Estado de Mato Grosso - UNEMAT. Cáceres, MT, 10 de julho de 2008. Disponível em: www.unemat.br. Acesso em: 15/fev/2012.

VENTURINI, J. C., PEREIRA, B. A. D., MORALES, R., FLECK, C. F.; BATISTELLA JUNIOR, Z. B.; NAGEL, M. B. (2010). Percepção da avaliação: um retrato da gestão pública em uma instituição de ensino superior. Revista de Administração Pública, v. 44, n. 1, p. 31-53.

THOMPSON, Fred; JONES, L. R. (1986). Controllership in the Public Sector. Journal of Policy Analysis and Management. New Jersey: John Wiley \& Sons, v. 5, n. 3. p. 547571.

YIN, Robert K. (2010). Estudo de caso: planejamento e método. (4 ed.). Porto Alegre: Bookmam.

Data de Submissão: 24/04/2012

Data de Aceite: 19/05/2014 